\title{
Alchimie urbaine
}

Urban Alchemy

Hilary Powell

\section{(2) OpenEdition}

Journals

Édition électronique

URL : https://journals.openedition.org/tc/7866

DOI : $10.4000 /$ tc. 7866

ISSN : 1952-420X

\section{Éditeur}

Éditions de l'EHESS

\section{Édition imprimée}

Date de publication : 31 octobre 2016

Pagination : 162-165

ISBN : 9782713225291

ISSN : 0248-6016

\section{Référence électronique}

Hilary Powell, « Alchimie urbaine », Techniques \& Culture [En ligne], 65-66 | 2016, mis en ligne le 31 octobre 2016, consulté le 29 septembre 2022. URL : http://journals.openedition.org/tc/7866 ; DOI : https://doi.org/10.4000/tc.7866 


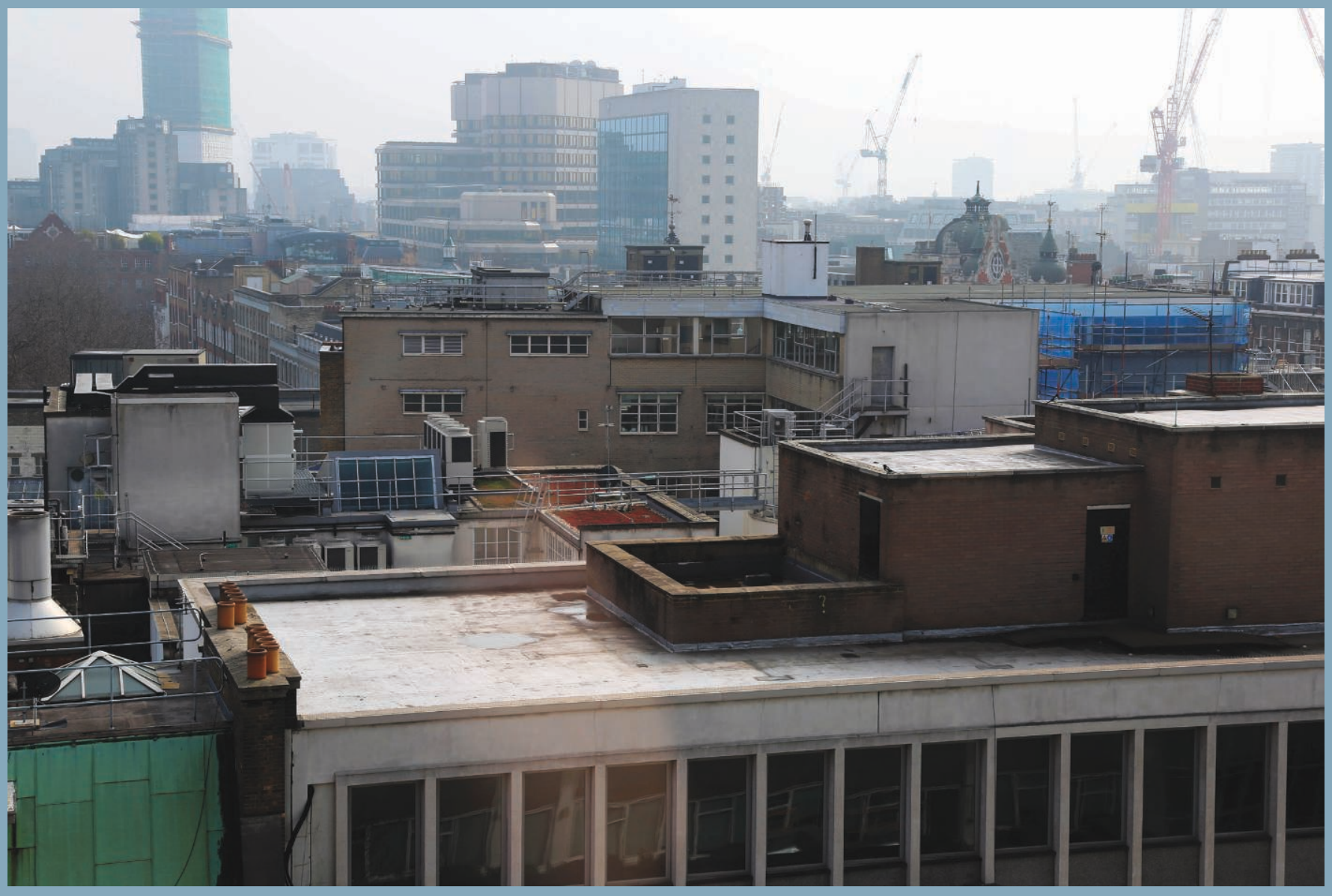




\section{Alchimie urbaine}

Lartiste Hilary Powell examine les divers matériaux utilisés sur les chantiers de démolition - du zinc au cuivre, en passant par l'acier, le béton, la brique, l'amiante, le mortier de chaux, le ciment, le plomb et l'ardoise. En rapport direct avec ces matériaux, elle nous raconte leur histoire et crée des portraits, tant des chantiers de démolition que des hommes qui y travaillent. Par le biais d'un travail original de récupération des matériaux, elle étudie les phénomènes de réhabilitation et de transition économique en utilisant les vestiges matériels issus du déclin industriel à des fins artistiques. La production créative et la poétique de ces lieux s'allient à la science, l'action et l'écologie politique des matériaux, dans cette étude interdisciplinaire des cycles de vie et de la micro/macro économie de la culture matérielle des paysages post-industriels. Le projet porte essentiellement sur les questions trop souvent négligées et sous-estimées des procédés, des matériaux, de la vie et des conditions d'existences des ouvriers, et interroge la façon dont nous utilisons et jetons les matériaux, ainsi que la valeur qu'on accorde à ces derniers.

Le projet a débuté par un travail mené sur des chantiers de démolition dans le cadre d'une bourse de recherche de l'Arts and Humanities Research Council (AHRC) dans le domaine des arts créatifs et du spectacle vivant (Creative and Performing Arts) à la Bartlett School of Architecture du Collège universitaire de Londres (UCL). Le projet s'est poursuivi au moment où Hilary est devenue «artiste en résidence Leverhulme» au sein du département de chimie de l'UCL, elle collaborait avec le département d'anthropologie dans le cadre du prix Sustainable Cities Grand Challenges de l'UCL pour son travail intitulé « Deconstructing Demolition : Journeys through Scrap and Salvage» («Déconstruire la démolition: voyage à travers la ferraille et la récupération»), en vue des épreuves, des gravures, des tirages et de la publication de son livre Urban Alchemy (Alchimie urbaine). 
Zinc on the skip en train d'être récupéré. L'artiste Hilary Powell en train de s'approprier du zinc de couverture sur le chantier de récupération de métaux.

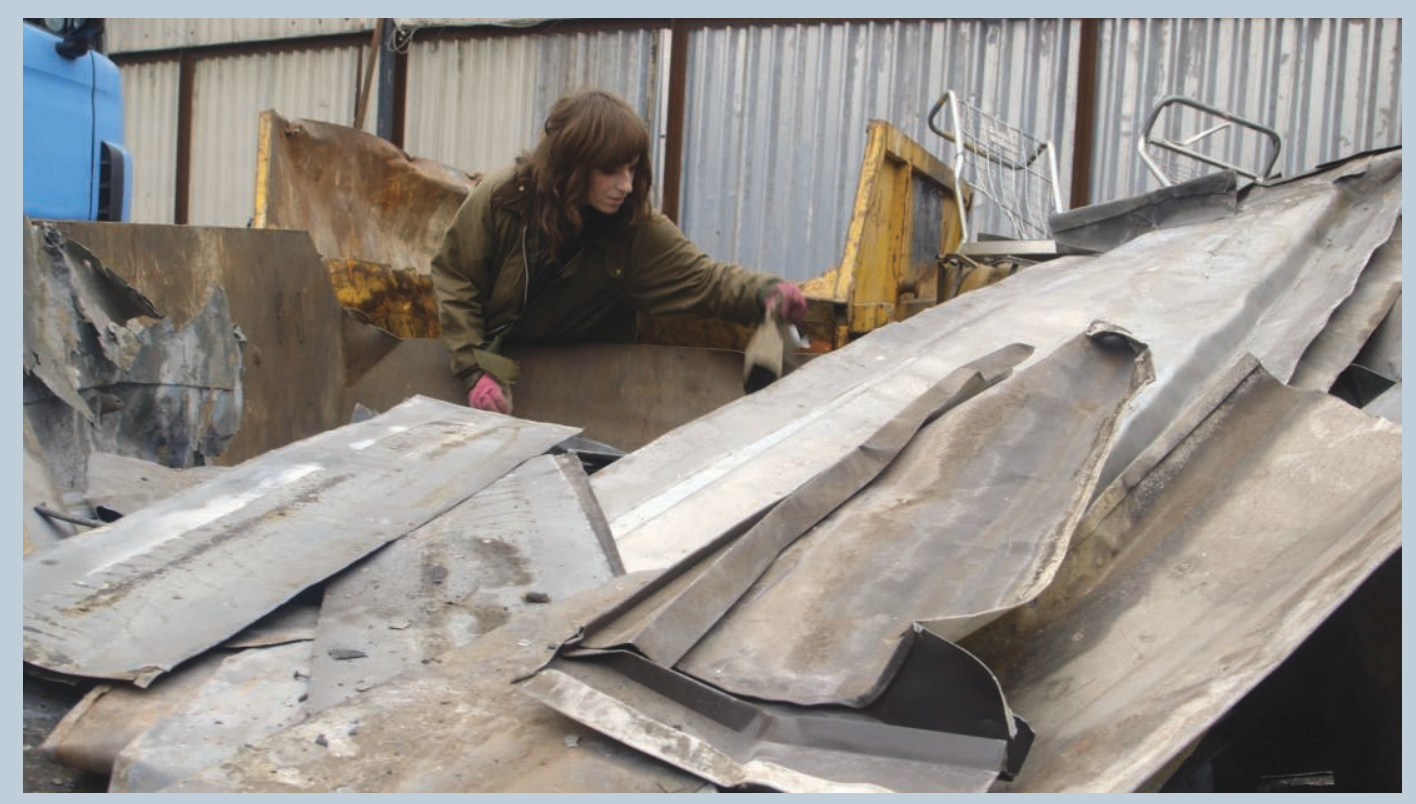

Zinc à l'atelier d'estampe. Bandes de zinc de couverture attendant d'être nettoyées à l'atelier d'estampe.
Zinc plongé dans l'acide. Aperçu d'une image en train de prendre forme au moment où le zinc, traité avec un nuage de poudre de résine d'aquatinte chauffée, est mordu à l'acide nitrique.
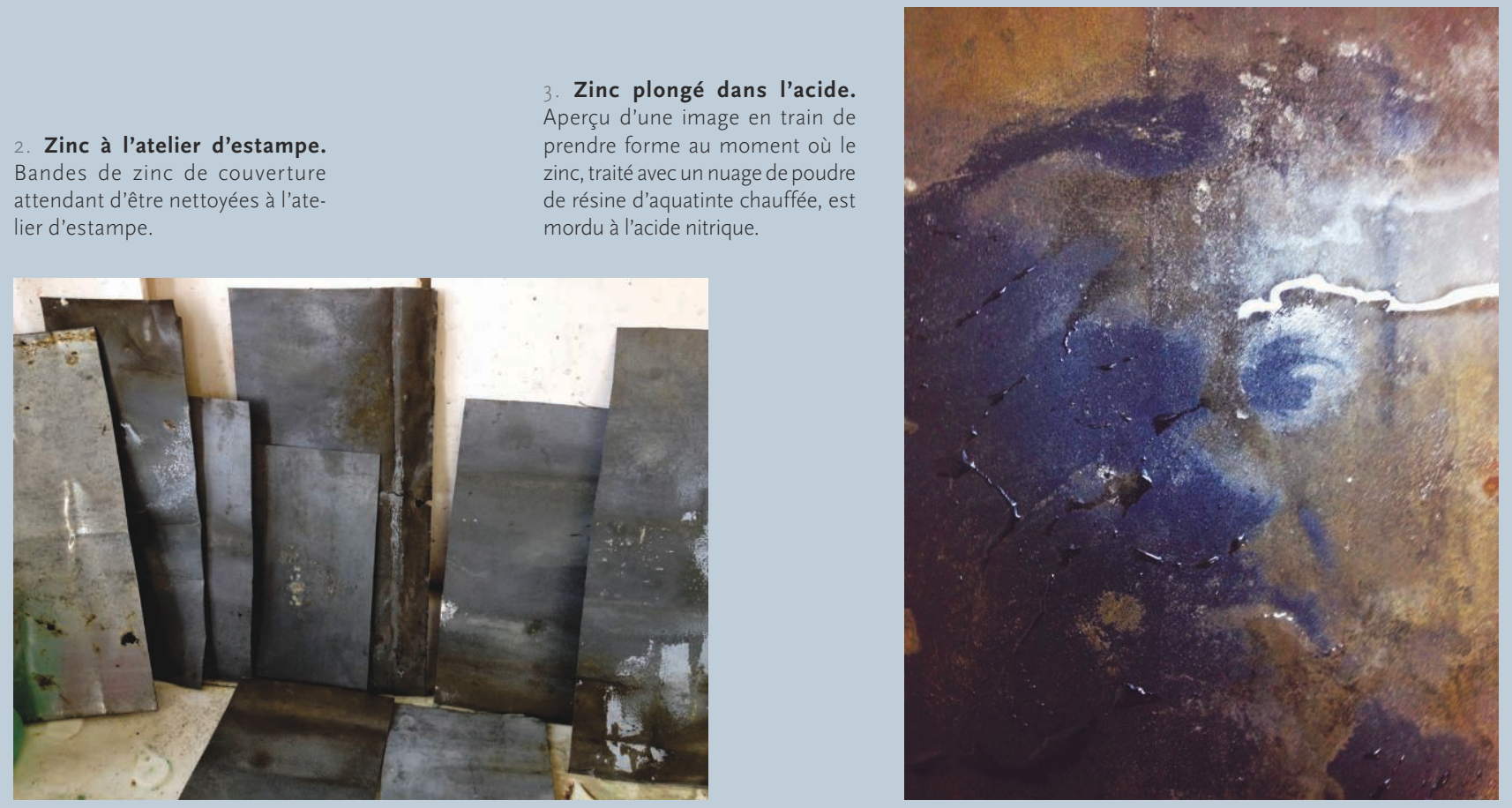


\section{En ligne}

Retrouvez l'article complet en version originale (anglais) sur revues.org, TechniquesE Culture 65-66 « Réparer le monde. Excès, reste et innovation $»:$ http://tc.revues.org/.

\section{I'auteure}

Lartiste Hilary Powell travaille avec des procédés, matériaux, personnes et endroits oubliés ou mésestimés, en utilisant un large éventail de supports. Sa pratique artistique est axée sur la récupération créative qui l’a menée sur le site du stade olympique rénové de Londres, dans des zones urbaines inexploitées et sur des sites de démolition. Ses récents projets intègrent également la réalisation de portraits des derniers mineurs de charbon du Sud du Pays de Galles, imprimés à partir de la pierre avec de la poudre de charbon, ainsi que l'invitation d'un groupe d'enfants d'un terrain de jeux du quartier à lui prêter main-forte dans le projet de destruction créative de la Tour Est de la BBC TV. www.hilarypowell.com.

\section{Iconographie}

Image d'ouverture. Toits du centre-ville de Londres recouverts de zinc et cuivre.

Crédits photographiques pour l'ensemble des images. (C) Hilary Powell

\section{Pour citer cet article}

Powell, H. 2016 «Alchimie urbaine», Techniques ECulture 65-66 «Réparer le monde. Excès, reste et innovation», p. 162-165.

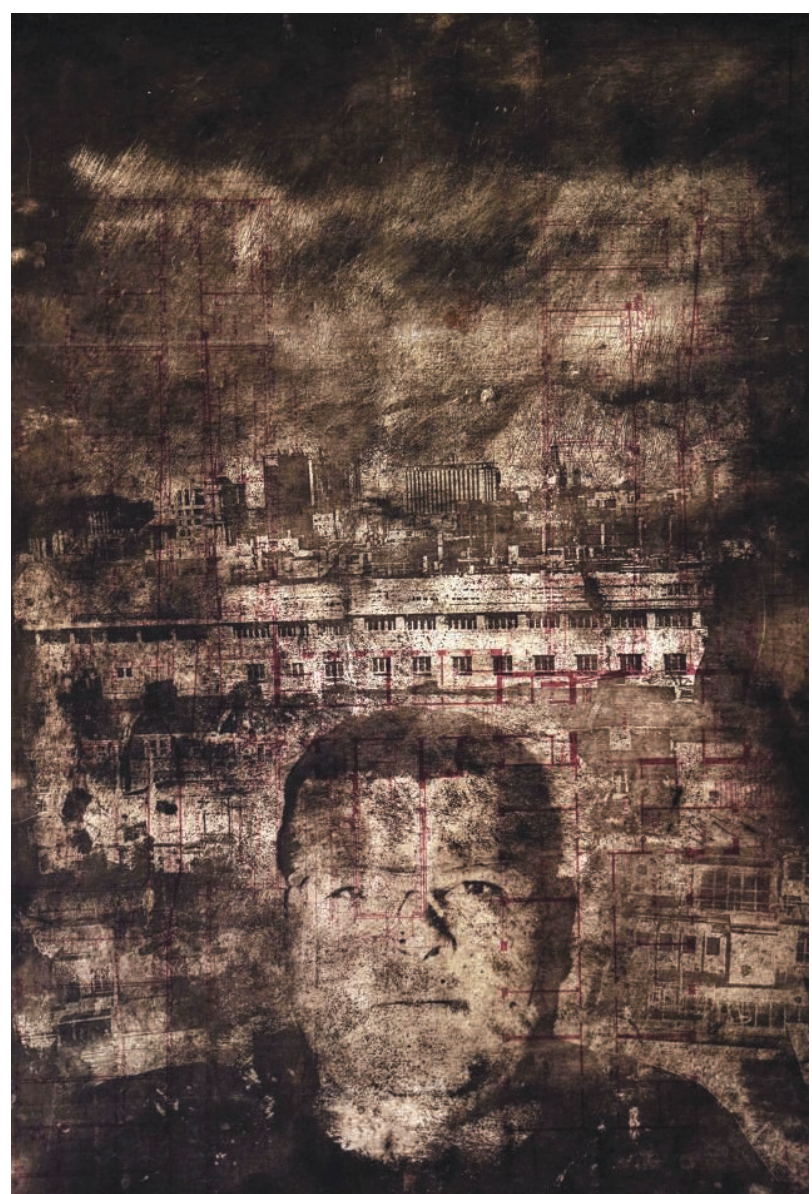

4. Épreuve finale sur des plans d'architecte récupérés. Portrait de Lybomir, ouvrier travaillant sur un chantier de démolition. Épreuve finale à partir d'une plaque de zinc récupérée et imprimée sur des vieux plans d'architecte recyclés. 